\title{
Oral magnesium supplementation modulates hepatic and intestinal expression of some carbohydrate metabolizing genes in type 2 diabetic rats
}

\begin{abstract}
Aim: This study was carried out to determine the effects of magnesium supplementation on Glucose transporter 4 (GLUT-4), Phosphofructokinase 1 (PFK-1) and Glucagon likepeptide 1 (GLP-1) in type 2 streptozotocin-nicotinamide induced diabetic rats.

Methods: Total of 24 Wister rats $(n=6)$ were used for this study and the treatment was for 28 days. Group 1: Rats (Normal Control) orally given distilled water; Group 2: Metformin treated diabetic rats orally given $100 \mathrm{mg} / \mathrm{kg}$ body weight metformin; Group 3: Orally given $100 \mathrm{mg} / \mathrm{kg}$ body weight metformin with $1000 \mathrm{mg} / \mathrm{kg}$ body weight magnesium supplement; Group 4: Diabetic Untreated control rats given distilled water. Measured data was analyzed statistically using Analysis of Variance (ANOVA) and graphically by Graph prism 8.0.2. Tukey test was used as the Post hoc test and statistical significance was considered at $\mathrm{p}<0.05$.

Results: The GLUT-4 expression of Group 3 were significantly $(\mathrm{p}<0.05)$ higher when compared with Group 4. However, Group 1 expression of GLUT-4 was significantly $(\mathrm{p}<0.05)$ high in comparison with the Diabetic Groups. Group 3 was significantly $(\mathrm{p}<0.05)$ higher when compared with Group 2 in the mRNA expression of PFK-1 at week 4. There was significant $(p<0.05)$ increase in the expression of GLP-1 of the treated rats but the metformin-magnesium supplement treated group showed higher value when compared with Diabetic Untreated Group. Moreover, Group 3 induced a significant $(\mathrm{p}<0.05)$ increase in the expression of GLP-1 in comparison with Group 2 while the Normal control was significantly $(p<0.05)$ higher than the Diabetic groups. This study demonstrates that magnesium may mediate effective metabolic control by stimulating the insulin sensitivity, and increased levels of GLUT-4, PFK-1 and GLP-1 in diabetic rats.
\end{abstract}

Conclusion: This suggests magnesium supplementation as an adjunct therapy with metformin, helps in improving GLUT-4, PFK-1 and GLP-1 expression.

Keywords: metformin, magnesium supplement, glucose transporter 4, phosphofructokinase 1, glucagon like-peptide 1
Volume 4 Issue 6 - 2019

Oluwaseun Fapohunda, Oluwarotimi Balogun Department of Biochemistry, Adekunle Ajasin University, Nigeria

Correspondence: Oluwaseun Fapohunda, Department of Biochemistry, Faculty of Science, Adekunle Ajasin University, Akungba Akoko, Nigeria, Tel +2347062998896, Email oluwaseun.fapohunda@aaua.edu.ng

Received: September 24, 2019 | Published: November 04, 2019
Abbreviations: DM, diabetes mellitus; IDDM, insulindependent diabetes mellitus; NIDDM, non-insulin dependent diabetes mellitus; GLP-1, glucagon like-peptide-1; ANOVA, analysis of variance

\section{Introduction}

Diabetes mellitus (DM) is a common and prevalent metabolic disorder characterized by hyperglycemia and abnormal lipid and protein. ${ }^{1}$ It is one of the five leading causes death in the world affecting both developed and developing countries alike. It was projected that about 300 million people will have the disease by the year 2025. ${ }^{2}$ According to ${ }^{3}$ the main indication of diabetes mellitus is the hyperglycemia in blood which is due to inappropriate pancreatic insulin secretion or low insulin-directed fostering of glucose by target cells. Diabetes mellitus is divided into several categories but the two major types are type 1 and type 2 . Type 1 known as Insulindependent diabetes mellitus (IDDM) is autoimmune disorder caused by auto aggressive T-lymphocytes that infiltrate the pancreas and destroy insulin producing $\beta$-cells leading to hypoinsulinemia and thus hyperglycemia. ${ }^{4,5}$ Type 2 is known as non-insulin dependent diabetes mellitus (NIDDM). It is characterized by insulin resistance in insulintargeting tissues, mainly the liver, skeletal muscle, and adipocytes. ${ }^{6}$

Treatment of DM takes multimodal therapeutic approach due to its multifactorial pathogenesis. The three main forms of treatment include: (i) diet and exercise, (ii) insulin replacement therapy and (iii) the use of oral hypoglycemic agents. ${ }^{7}$

There are many oral hypoglycemic agents for the management of type-2 diabetes currently, such as biguanides and sulfonylureas, but these synthetic agents are associated with certain adverse side effects (such as hypoglycemia, drug resistance, dropsy and weight gain) and even toxicity. ${ }^{1,2}$ In addition, these therapeutic measures have inadequate efficacy or significant mechanism-based adverse effect when used as a combined therapy. Hence, there is need for drug 
that has fewer side effects and elicit less hypersensitivity with high anti-diabetic regulations. Therefore, it becomes imperative to explore and discover alternative drugs and dietary supplement or therapeutic adjunct which are safer and more effective.

Magnesium is the fourth most abundant cation in the human body and the second most predominant intracellular cation after potassium. ${ }^{8}$ Being an indispensable element, it is involved in nearly all vital physiological processes (including glycolysis) essential for survival of living organisms. It was reported by that the link between diabetes mellitus and magnesium is well established. Many enzymes in the liver require Magnesium $\left(\mathrm{Mg}^{2+}\right)$ for their activity ${ }^{10}$ including pacemaker enzymes in the glycolytic pathway (e.g. phosphofructokinase-1, PFK1). $\mathrm{Mg}^{2+}$ deficiency occurs during diabetes induction ${ }^{11}$ this should concomitantly affect the level of PFK-1 in a diabetic subject because $\mathrm{Mg}^{2+}$ is an important cofactor for the catalytic activity of this enzyme. Hence, the expression of PFK-1 gene was investigated in this present study. It was also examined whether $\mathrm{Mg}^{2+}$ affects GLUT-4 mRNA gene expression.

Glucagon like-peptide-1 (GLP-1) is produced through posttranslational processing of proglucagon and acts as a regulator of various homeostatic events. GLP-1 is synthesized in small amounts in the pancreas. It induces insulin production in developing, and to a lesser extent in the adult intestinal epithelial cells. It was earlier suggested by ${ }^{12}$ that GLP-1 production when induced in intestinal epithelial cells could represent a new therapeutic approach to diabetes mellitus.

\section{Materials and methods}

\section{Materials; reagents}

Citric acid, Sodium citrate, picric acid, Chloroform, Magnesium Sulfate $\left(\mathrm{MgSO}_{4}\right.$, Sigma Aldrich, Hamburg, Germany), Metformin (Merck pharma care spoxil), Nicotinamide (NAD), Streptozotocin (STZ, Sigma Aldrich, Hamburg, Germany), Sanitizer, Sucrose (Dangote PLC), Master mix (Biolabs, New England), Trizol (Lysis Solution Zymo Research, USA), Citric buffer solution, Agarose gel powder(Cleaver Scientific LTD-AG-100), Primers(Inqaba Biotechnical industries (pty) LTD, South Africa), Nuclease-free water (Life Science advanced technologies, England), Reverse transcriptase (Biolabs, New England), Random Primer (Biolabs, New England), Ethanol and Deoxynucleotide (dNTPs) solution mix (Biolabs, New England), Ethidium bromide, TBE buffer solution (Trisborate EDTA). All chemicals used were of analytical grade.

\section{Animals}

Twenty-four (24) male wister rats (average weight of $150 \mathrm{~g}$ ) were obtained from the Department of Plant Science and Biotechnology, Adekunle Ajasin University Ondo State, Nigeria. They were housed under standardized environmental conditions (well-ventilated room, with 12 hour light-dark cycles and $55 \pm 4 \%$ at $24 \pm 2^{\circ} \mathrm{C}$ ). Standard pellet chow and water were given ad libitum.

They were divided into groups $(n=6)$ based on their weight which was used to calculate the dosage of STZ, NAD, MgSO4 and metformin administered. Induction was carried out after three weeks of acclimatization. Administration started when the Wister rats were confirmed diabetic after 72 hours of induction. The intervention was carried out daily in the following order for four (4) weeks:

Group 1: Normal control rats given distilled water.

Group 2: Metformin treated rats were given $100 \mathrm{mg} / \mathrm{kg}$ body weight.

Group 3: Metformin + Magnesium treated rats were given $100 \mathrm{mg} / \mathrm{kg}$ and $1000 \mathrm{mg} / \mathrm{kg}$ body weight respectively.

Group 4: Diabetes untreated rats given distilled water.

\section{Methods}

\section{Induction of diabetes in rats}

NIDDM was induced as described by ${ }^{13}$ with little modification. Briefly, overnight-fasted rats were given intraperitoneal injection (i.p.) of freshly prepared $60 \mathrm{mg} / \mathrm{kg} \mathrm{STZ}$ (dissolved in a citrate buffer of $\mathrm{pH} 4.8$ ), 5 minutes after the i.p. administration of $110 \mathrm{mg} / \mathrm{kg}$ of freshly prepared NAD dissolved in normal saline.

\section{Intervention}

Magnesium sulfate and metformin were intubated into the mouth of the diabetic rats in quantity based on their body weights.

\section{Sacrificing of animals and collection of tissue}

At the end of 28 days' treatment, the animals were subjected to fasting overnight and were sacrificed after 9 hours following ethical protocol. All experimental rats in each group were subjected to cervical dislocation following the ethical care and handling of experimental animals' regularities and they were dissected using Dissecting set. The rats were sacrificed and tissues of interest (liver and intestinal crypt) were excised from each experimental animal. Little quantity of the excised tissues was dropped in eppendorf tubes containing $0.2 \mu \mathrm{ml}$ TRIzol across the groups and spin using laboratory centrifuge.

\section{Gene expression profiling}

\section{RNA extraction}

$50 \mu \mathrm{l}$ of TRIzol ${ }^{\circledR}$ Reagent was added to the tissue sample. Sample was homogenized using a glass Teflon ${ }^{\circledR}$ or power homogenizer. Homogenized sample was incubated for 5 minutes at room temperature to permit complete dissociation of the nucleoprotein complex. $100 \mu \mathrm{l}$ of equal volume of chloroform per $50 \mu$ l of TRIzol ${ }^{\circledR}$ Reagent was used for homogenization. The tube containing the samples was vigorously shaken by hand for 15 seconds. The samples were incubated for 2-3 minutes at room temperature. The samples were centrifuged at 4000 $\mathrm{rpm}$ for 30 minutes at $4^{\circ} \mathrm{C}$. The aqueous phase of the sample was removed by angling the tube at $45^{\circ}$ and pipetting the solution out. The aqueous phase removed was placed into a new tube and proceeded to the RNA Isolation Procedure. $100 \mu$ l of $100 \%$ isopropanol was added to the aqueous phase, per $1 \mathrm{ml}$ of TRIzol ${ }^{\circledR}$ Reagent used for homogenization. The samples were incubated at room temperature for 10 minutes and centrifuge at $4000 \mathrm{rpm}$ for 30 minutes at $4^{\circ} \mathrm{C}$. The supernatant was discarded from the tube, leaving only the RNA pellet. The pellet was washed with $100 \mu \mathrm{l}$ of $70 \%$ ethanol per $50 \mu \mathrm{l}$ of TRIzol ${ }^{\circledR}$ Reagent used in the initial homogenization. The samples were "vortexed" briefly and then centrifuged at $4000 \mathrm{rpm}$ for 5 minutes at $4{ }^{\circ} \mathrm{C}$. The ethanol used for washing was discarded. The RNA pellet was air dried for 5-10 minutes. RNA was re-suspended in $50 \mu 1$ of sterile, nuclease-free water. 


\section{Complimentary DNA (cDNA) synthesis}

By adding $2 \mu 1$ reverse transcriptase from the cocktail containing (1) the random oligo primer (2) the dNTP's (3) the reverse transcriptase and (4) the reverse transcriptase buffer (5) nuclease-free water, reverse transcription was performed. $2 \mu 1$ reverse transcriptase was aliquot into $20 \mu$ of total RNA across the samples for the conversion into cDNA. The sample is then incubated in the thermocycler running for 1 hour at $65^{\circ} \mathrm{C}$ in a total reaction volume of $22 \mu 1$ for the conversion

\section{Quantitative real-time polymerase chain reaction (PCR)}

The amplification was performed using an optimization. Template (cDNA) $2 \mu 1$, nuclease-free water $4 \mu \mathrm{l}$, forward primers $1 \mu 1$ and reverse primers $1 \mu \mathrm{l}$ and master mix $2 \mu \mathrm{l}$. All these reagents follow each sample for complete enzymatic reaction. The PCR was carried out using multigen optimax PCR machine (Serial Number: 1405010). Amplification conditions were: $94^{\circ} \mathrm{C}$ pre-denaturation for $5 \mathrm{~min}$, denaturation at $94^{\circ} \mathrm{C}$ for 30 seconds, Annealing $55^{\circ} \mathrm{C}(\mathrm{Tm})$ for 30 seconds and Extension $72^{\circ} \mathrm{C}$ for 30 seconds and then $5 \mathrm{~min}$ at $72^{\circ} \mathrm{C}$ by 35 cycles. Expression levels of PFK-1, GLUT-4 and GLP1 were normalized by Glyceraldehyde-3-phosphate dehydrogenase (GAPDH). The sequence of specific primer sets for each gene, amplicon sizes and annealing temperature of the primers real-time PCR time was used (Table 1).

Table I List of PCR Primer

\begin{tabular}{|c|c|c|}
\hline $\begin{array}{l}\text { Target } \\
\text { gene }\end{array}$ & Forward 5'-3' & Reverse 3'-5' \\
\hline GAPDH & $\begin{array}{l}\text { TGA AGG TCG GAG TCA } \\
\text { ACG GAT TTG GT }\end{array}$ & $\begin{array}{l}\text { CAT GTG GGC CAT } \\
\text { GAG GTC CAC CAC }\end{array}$ \\
\hline GLUT 4 & $\begin{array}{l}\text { GCA ACA TGT CAG AAG } \\
\text { ACA AGA TCA }\end{array}$ & $\begin{array}{l}\text { TAG CTC TTC GGT } \\
\text { CAT CCA GAG }\end{array}$ \\
\hline PFK-I & $\begin{array}{l}\text { CTG CAT CGG ACT CTA } \\
\text { CCA GG }\end{array}$ & $\begin{array}{l}\text { AGG GAAAGG CAG } \\
\text { TGG GTCTA }\end{array}$ \\
\hline GLP-I & $\begin{array}{l}\text { ATC AAA GAC GCT GCC } \\
\text { CTC AA }\end{array}$ & $\begin{array}{l}\text { CCA CGC AGT ATT } \\
\text { GCA TGA GC }\end{array}$ \\
\hline
\end{tabular}

\section{Gel electrophoresis}

Assessment of Polymerase Chain Reaction products (amplicons) were electrophoresed in $0.5 \%$ of agarose gel using $0.5 \mathrm{x}$ TBE buffer (2.6 $\mathrm{g}$ of Tris base, $5.4 \mathrm{~g}$ of Tris boric acid and $2 \mathrm{ml}$ of $0.5 \mathrm{M}$ EDTA and adjusted to $\mathrm{pH} 8.2$ with the sodium hydroxide pellet). $0.5 \mathrm{~g}$ of agarose powder was weighed and added to $50 \mathrm{ml}$ of $0.5 \mathrm{x}$ TBE buffer and was put in the microwave to heat for 45 seconds until agarose dissolved. $0.2 \mu \mathrm{l}$ of ethidium bromide was added to aid visualization and $2 \mu 1$ of tracking dye was added to each sample (amplified gene). The agarose was poured into the gel tray with the combs and allowed to stay for 15 minutes for agarose to solidify; the gel box was filled with buffer. The combs were carefully removed, then $8 \mu 1$ of the samples were carefully loaded into the wells and the gel was run for 15 minutes at $100 \mathrm{~V}$. The expression products were visualized as bands by UV-transilluminator (foto/photophoresis, Serial Number: FPG1 02046277).

\section{Data and statistical analysis}

Data are expressed as Mean \pm standard error of mean (SEM). Statistical analyses were carried out using one-way Analysis of variance (ANOVA), with graphical representation done using Graph prism 8.0.2. (Graph pad software, San Diego California, USA). Tukey test was used as the post-hoc test and statistical significance was considered at $95 \%$ confidence interval $(\mathrm{p}<0.05)$.

\section{Results \& discussion}

Diabetes Mellitus (DM) is an endocrinological disorder and not a single disorder but a group of metabolic or heterogeneous afflictions resulting from an irregularity in insulin secretions, insulin actions or both..$^{14,15}$ The failure of pancreatic beta cells to produce insulin, and the impairment of insulin action, play a central role in the disruption of glycemic homeostasis, leading to hyperglycemia, a hallmark of DM. ${ }^{16}$ At present, optimized glucose control is recognized as the best approach to reduce the risk of diabetes chronic complications. ${ }^{17}$ The present study was designed to investigate the effect of oral magnesium supplementation as adjunct therapy with metformin on PFK-1, GLUT4 and GLP-1 genes.

Glucose transporter controls the rate of glucose utilization. In hepatic tissue there are three glucose transporters: Glucose transporter 1, 3 and 4 (GLUT-1, GLUT-3 and GLUT-4). Insulin increases uptake rate of glucose mainly by stimulating the translocation of the GLUT4 isoforms from intracellular pools to the surface cell membrane by increasing rate of glucose transport. ${ }^{18}$

This present study showed that there was significant $(\mathrm{p}<0.05)$ difference in the expression of GLUT-4 gene in the diabetic groups when compared with the Normal Control group. This is an indicator of defective expression of GLUT-4 in diabetic state which is one of the hallmarks of type 2 diabetes. This result is in tandem with the findings of ${ }^{18}$ who reported that there was down-regulation of GLUT4 in diabetic subjects. All the Diabetic groups showed reduced level of GLUT-4 gene expression compared to the Normal Control as seen in Figure 1. Comparison was carried out between the treated and the untreated groups and the expression of GLUT-4 was significantly $(p<0.05)$ higher in the treated groups than the diabetic untreated group. However, there was a significant $(\mathrm{p}<0.05)$ increase in the expression of GLUT-4 in the group administered with $\mathrm{MgSO}_{4}(1000$ $\mathrm{mg} / \mathrm{kg})$ and metformin $(100 \mathrm{mg} / \mathrm{kg})$ compared to the group treated with Metformin only, suggesting that Mg mediates effective metabolic control by autophosphorylation and stimulation of insulin which elicit the translocation of GLUT-4 from an intracellular pool to the plasma membrane thereby facilitating glucose transport and lowering blood glucose level according to. ${ }^{19}$ Hence, it appears that the modulated expression of GLUT-4 in insulin target hepatic tissues influences the regulation of glucose uptake and metabolism as well as reflecting the situation of the whole-body insulin resistance, which is a major factor in the pathogenesis of T2DM.

PFK-1 is an allosteric enzyme and it is critical for the metabolic regulation of the glycolytic pathway. Although, phosphorylase responds to an extra-cellular stimulus, PFK-1 is sensitive to the intracellular level of several allosteric effectors. Pi, ADP, AMP and fructose 2, 6-bisphosphate are positive effectors, which stimulate PFK-1 activity that is, increases the level of fructose 2,6-bisphosphate in the cell. ${ }^{20}$ The stimulation of these PKF-1 enzymes by insulin in the hepatic tissues which leads to enhanced glycolysis, is of fundamental metabolic importance for the following reasons: (1) when glycogen store in liver is replete, the glucose is converted to lactate, to maintain enhanced glucose utilization and (2) lactate produced and released by muscle and adipose tissue is taken up by liver and converted to 
glycogen. ${ }^{21}$ Moreover, the mRNA expression of PFK-1 at pH 8 was significantly $(\mathrm{p}<0.05)$ increased with $90 \mu \mathrm{g} / \mathrm{dl}$ and $100 \mu \mathrm{g} / \mathrm{dl}$ in GRP2 and GRP3 respectively but with a significant $(\mathrm{p}<0.05)$ decrease of 60 $\mu \mathrm{g} / \mathrm{dl}$ in untreated diabetic rats.

Wister rats in GRP4 (Diabetes Untreated) showed significant $(p<0.05)$ reduction in the level of PFK-1 expression when compared with the Normal Control (GRP1) rats in Figure 2. The graphical illustration in Figure 2 shows that rats in GRP4 were completely diabetic with shattered glycolytic pathway which cannot produce pyruvate that will go through TCA cycle. Hence, there will be reduced energy, body and muscle weakness. The treated and the untreated groups were also compared and the expression of PFK-1 was significantly $(p<0.05)$ higher in the treated groups than the Diabetic Untreated Group. There was a significant $(p<0.05)$ difference in the level of PFK-1 expression in the group administered with $\mathrm{MgSO}_{4}$ (1000 mg/kg body weight) and metformin (100 mg/kg body weight) compared to the Metformin treated Group. Most of enzyme(s) in the Glycolytic pathway are kinases or phosphorylase which requires $\mathrm{Mg}^{2+}$ as their cofactor. Increase in intracellular $\mathrm{Mg}$ helps to keep the enzyme in their activated form to continue the process of glucose conversion to pyruvate that will help to synthesize more ATP through Citric acid pathway and reduce risk of hyperglycemia. Activating protein kinase (AMPK) system is a key player in regulating energy balance at both the cellular and whole body level. Liver AMPK controls glucose homeostasis mainly through the inhibition of gluconeogenic gene expression and hepatic glucose production. $\mathrm{Mg}$ helps to activates AMPK in a calcium-dependent manner which in turn activates PFK-1 in the glycolytic pathway. ${ }^{22}$

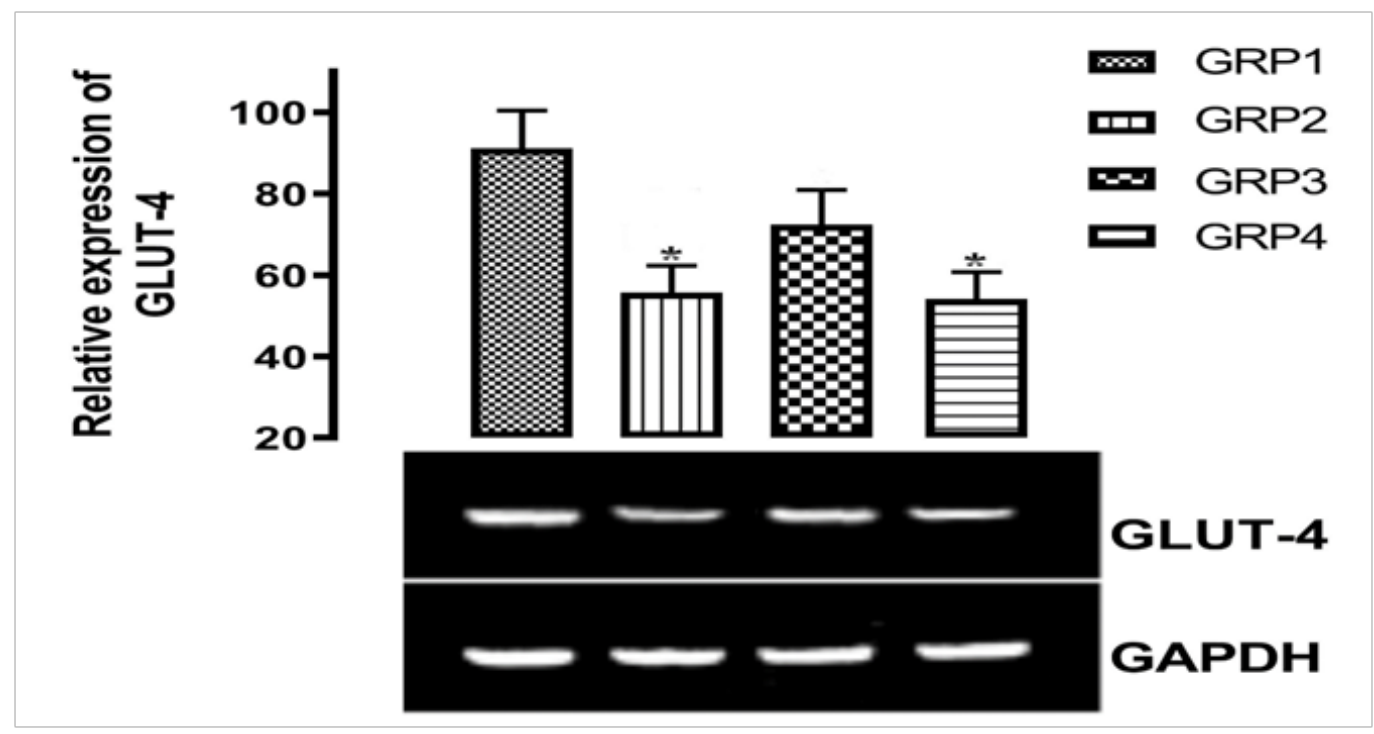

Figure I Effect of magnesium supplementation in the expression of glut-4 in the hepatic tissue.

(*) means significant difference $\mathrm{p}<0.05$ when compared with normal control (GRPI).

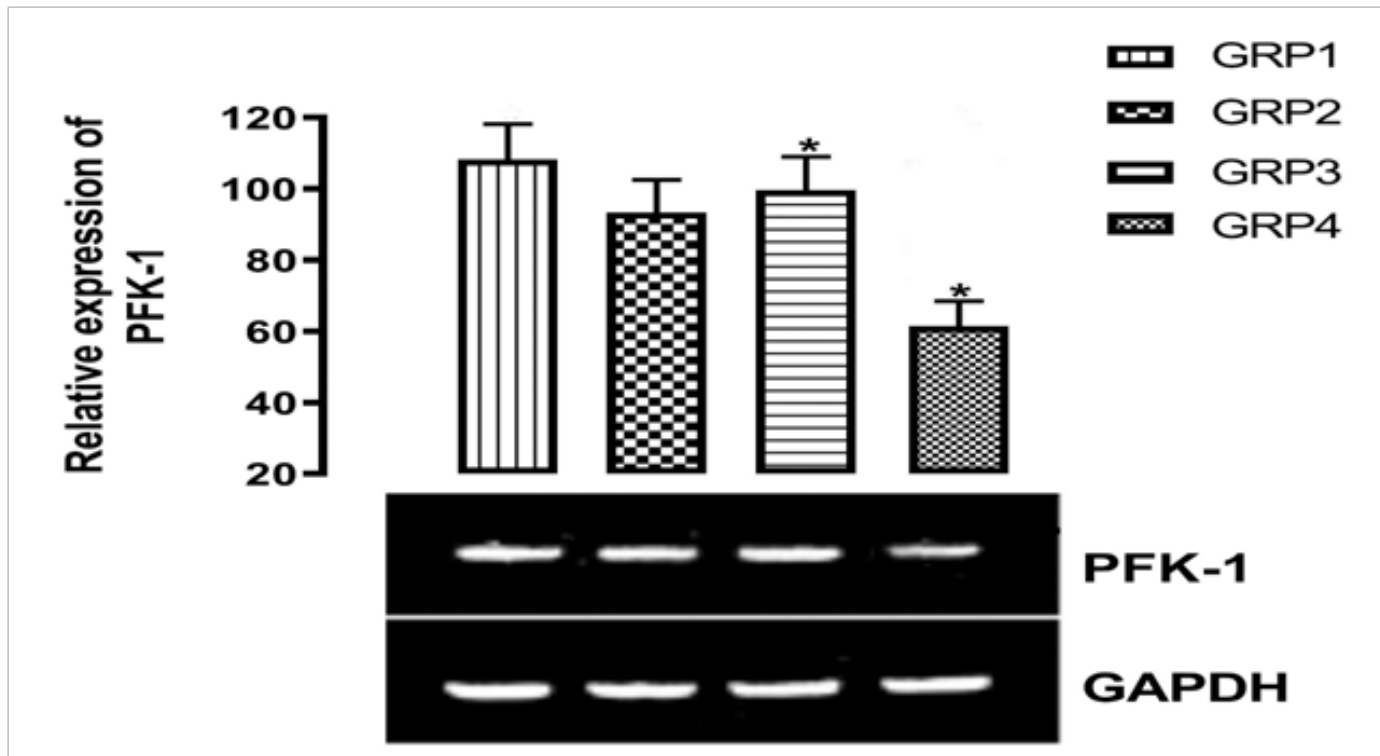

Figure 2 Effects of magnesium supplementation on phosphofructokinase (pfk-I) expression in the hepatic tissue. $\left(^{*}\right)$ means significant difference $p<0.05$ when compared with normal control (GRPI). 
The up regulation of GLP-1 increases the level of the hormones called 'incretins'. These hormones help the body to produce more insulin when needed and reduce the amount of glucose produced in the liver. Metformin induced a significant $(\mathrm{p}<0.05)$ increase in the expression of GLP-1 in GRP2 compared to GRP4 (Diabetic Untreated) as observed in Figure 3. This is consistent with the findings of ${ }^{23}$ who reported that in pooled rat model, metformin significantly inhibits degradation of GLP-1 (7-36) amide after 4 weeks of administration.

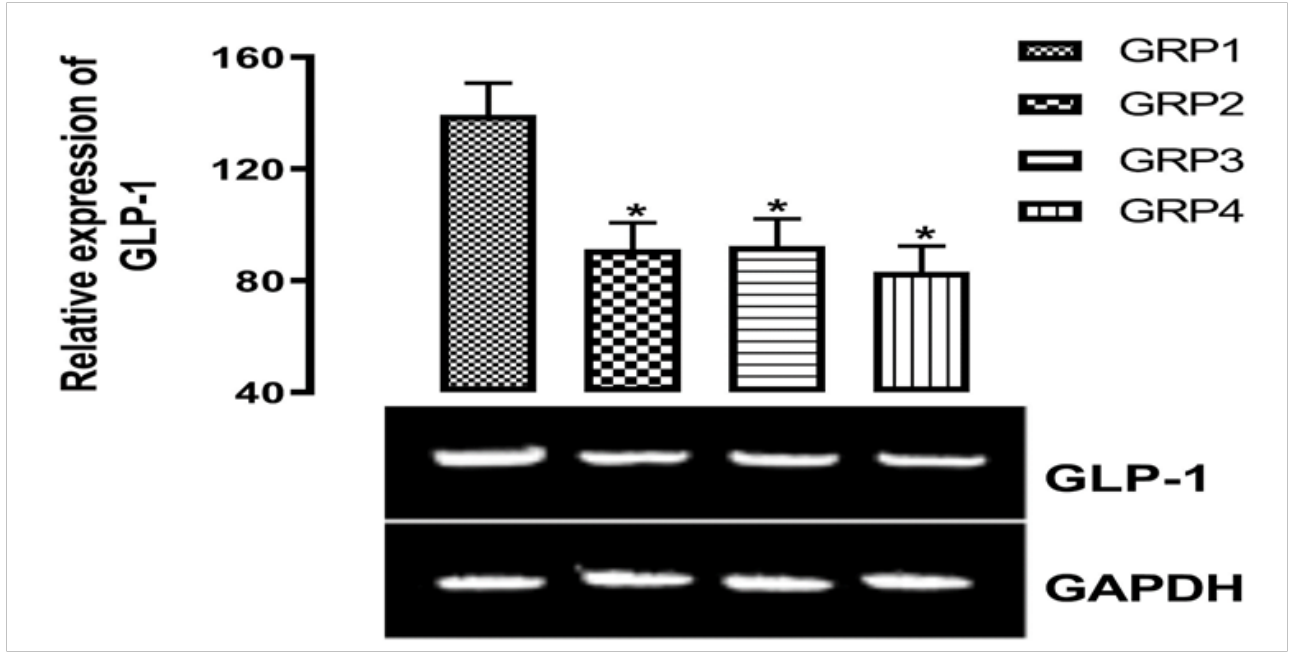

Figure 3 Regulatory effect of magnesium supplementation on the expression of glucagon like-peptide (glp-I) in the intestinal crypt.Asterisk (*) means significant difference $p<0.05$ when compared with normal control (GRPI).

Significant $(\mathrm{p}<0.05)$ increase of GLP-1 mRNA expression levels were observed in GRP2 and GRP3. These up regulation of GLP1 stimulates insulin secretion and reduce glucagon secretion in a glucose-dependent manner, improve satiety and promote weight loss. ${ }^{24,25}$ According to, ${ }^{26}$ increase in GLP-1 expression has been shown to improve cardiovascular outcomes and have high glucose lowering effect. The modulation and up-regulation of GLP-1 must have resulted from the inhibition of a gastrointestinal enzyme Dipeptidyl peptidase IV (DPP-4), because DPP-4 is an enzyme that degrades incretins.

\section{Conclusion}

Our results indicate that magnesium supplement offered more effective anti-diabetic property when used as adjuvant therapy with the standard anti-diabetic drug metformin than metformin alone, in glycemic control and activation of glycolytic pathway in liver. $\mathrm{Mg}^{2+}$ has both positive hepatic and intestinal effects.

\section{Acknowledgments}

This study acknowledges the technical support of the Director of center for Bioinformatics and Drug Design (CBDD) Adekunle Ajasin University, Dr. I.O. Omotuyi and Inyang Kayode for his assistance with the molecular assays.

\section{Funding}

No funding source supported this study.

\section{Conflicts of interest}

The authors declare that they have no competing interests.

\section{References}

1. Ying Guo, Rongji Dai, Yulin Deng, et al. Hypoglycemic activity of the extracts of Belamcanda chinensis leaves (BCLE) on KK-Ay mice. Biomed Pharmacother. 2019;110:449-455.
2. Elekofehinti OO. Saponins: Antidiabetic principles from medicinal plants- A review. Pathophysiology. 2015;22(2):95-103.

3. Deepthi B, Sowjanya K, Lidiya B, et al. A Modern Review of Diabetes mellitus: An Annihilatory Metabolic Disorder. Journal of In-Silico and In-vitro. Pharmacology. 2017;3:1.

4. Yadav UCS, Moorthy K, Baquer NZ. Effects of sodium orthovanadate and Trigonella foenum-graecum seeds on hepatic and renal lipogenic enzymes and lipid profile during alloxan diabetes. J Biosci. 2004;29(1):81-91.

5. American Diabetes Association Classification and diagnosis of Diabetes: Standards of Medical care in Diabetes. Diabetes Care. 2019;42(Supply 1):513-528.

6. Seely BL, Olefsky JM. Potential cellular and genetic mechanisms for insulin resistance in common disorders of obesity and diabetes. In: D Moller, Editor. Insulin resistance and its clinical disorders, Wiley, Chichester. 1993.

7. Ivorra MD, Paya M, Villar A. A review of natural products and plants as potential antidiabetic drugs. J Ethnopharmacology. 1989;27(3):243-275.

8. Jesse Bertinato. Bioactive food as dietary interventions for diabetes. 2edn. Magnesium and relationship with diabetes. Chapter 16: 2019;249-264.

9. Fapohunda O. Synergistic insulinotropic effect of metformin-Mg2+ adjunct supplement: A case study of streptozotocin-induced type 2 diabetes in sprague dawley rats. J Diabetes Metab Disord Control. 2018;5(2):38-46.

10. Gommers LM, Hoenderop JG, Bindels RJ, et al. Hypomagnesemia in Type 2 Diabetes: A Vicious Circle? Diabetes. 2016;65(1):3-13.

11. Barooti A, Kamran M, Kharazmi F, et al. Effect of oral magnesium sulfate administration on blood glucose hemostasis via inhibition of gluconeogenesis and FOXO1 gene expression in liver and muscle in diabetic rats. Biomed Pharmacother. 2019;109:1819-1825.

12. Maezaki H, Tawada M, Yamashita T, et al. Design of Potent Dipeptidyl peptidase IV (DPP-4) Inhibitors by employing a strategy to form salt bridge with Lys554. Bioorg Med Chem Lett. 2017;27(15):3565-3571. 
13. Venkateshwarlu Eggadi, Sharvana Bhava Bandaru Sheshagiri, Adukondalu Devandla, et al. Effect of Atorvastatin on Pharmacology of Sitagliptin in Streptozotocin Nicotinamide Induced Type-II Diabetes in Rats. Biol Med (Aligarh). 2015;7:1.

14. Jahan S, Fariduddin M, Sultana N, et al. Predictors of Post-Partum Persistence of Glucose Intolerance and Its Association with CardioMetabolic Risk Factors in Gestational Diabetes Mellitus. Journal of Diabetes Metabolism. 2015;6:10.

15. Lyons RA, Benvenuti L. Deposition and Distribution Factors for the Endocrine Disruptor, 4-Nonylphenol, in the Sierra Nevada Mountains, California, USA. J Environ Anal Toxicol. 2016;6:4

16. Thomas CC, Philipson LH. Update on diabetes classification. Med Clin North Am. 2015;99(1):1-16.

17. Yonamine CY, Pinheiro machado E, Michalani LM, et al. Resveratrol Improves Glycemic Control in Insulin-treated diabetes rats: Participation of the Hepatic Territory. Nutr Metab (Lond). 2016;13:44

18. Morakinyo AO, Samuel TA, Adekunbi DA. Magnesium upregulates insulin receptor and glucose transporter-4 in streptozotocin-nicotinamideinduced type-2 diabetic rats. Endocr Regul. 2018;52(1):6-16.

19. Leto D, Saltiel AR. Regulation of glucose transport by insulin: traffic control of GLUT-4. Nat Rev Mol Cell Biol. 2012;13(6):383-396.

20. Dimitriadis G, Parry Billings M, Bevan S, et al. The effects of insulin on transport and metabolism of glucose in skeletal muscle from hyperthyroid and hypothyroid rats. Eur J Clin Invest. 1997;27(6):475-483.
21. Dimitriadis G, Newsholme E. Integration of biochemical and physiologic effects of insulin on glucose metabolism. Exp Clin Endocrinol Diabetes. 2001;109(Supply 2):122-134.

22. Ming jun Chen, Xin Y, Yu qing C, et al. Phytochemicals for Noninsulin Diabetes Mellitus: A Mini review Plant-Derived Compounds Hypoglycemic Activity. Journal of Food and Nutrition Science. 2017;5(2):23-27.

23. Mannucci E, Ognibene A, Cremasco F, et al. Effect of metformin on glucagon-like peptide 1(GLP-1) and leptin levels in obese non-diabetic subjects. Diabetes Care. 2001;24(3):489-494.

24. Thrasher J. Pharmacologic management of type 2 diabetes mellitus: available therapies. Am J Med. 2017;130(6S):4-17.

25. Esposito K, Chiodini P, Maiorino MI, et al. Glycaemic du- rability with dipeptidyl peptidase- 4 inhibitors in type 2 diabetes: a systematic review and meta-analysis of long-term randomised controlled trials. BMJ Open. 2014;4:005442.

26. Htike Z, Zaccardi F, Papamargaritis D, et al. Efficacy and safety of glucagon-like peptide-1 receptor agonists in type 2 diabetes: a systematic review and mixed-treatment comparison analysis. Diabetes Obes Metab. 2017;19(4):524-536. 